\title{
Effect of aspirin treatment on the prevention of esophageal adenocarcinoma in a rat experimental model
}

\author{
PAULA ESQUIVIAS ${ }^{1}$, CARMELO CEBRIÁN $^{3}$, ANTONIO MORANDEIRA ${ }^{2}$, \\ SONIA SANTANDER ${ }^{4}$, JAVIER ORTEGO ${ }^{3}$, MARÍA ASUNCIÓN GARCÍA-GONZÁLEZ ${ }^{1,5,6}$, \\ ANGEL LANAS $^{1,4,6,7}$ and ELENA PIAZUELO ${ }^{1,5,6}$
}

\author{
${ }^{1}$ CIBER Enfermedades Hepáticas y Digestivas, 08036 Barcelona; Departments of ${ }^{2}$ Surgery and ${ }^{3}$ Pathology, \\ University Hospital, 50009 Zaragoza; ${ }^{4}$ University of Zaragoza, 50009 Zaragoza; ${ }^{5}$ Aragon Health Science Institute, \\ 50009 Zaragoza; ${ }^{6}$ Instituto de Investigación Sanitaria Aragón (IIS Aragon), 50009 Zaragoza; \\ ${ }^{7}$ Department of Gastroenterology, University Hospital, 50009 Zaragoza, Spain
}

Received January 23, 2014; Accepted March 13, 2014

DOI: 10.3892/or.2014.3137

\begin{abstract}
Aspirin has been proposed in recent years as a candidate for chemoprevention of adenocarcinoma in patients with Barrett's esophagus. The aim of the present study was to evaluate the effect of acetylsalicylic acid (ASA) in an experimental model of esophageal adenocarcinoma. An animal model of gastroenteroesophageal reflux was established using Wistar rats undergoing esophagojejunostomy with gastric preservation. Following surgery, rats were divided into three groups: i) control (vehicle); ii) ASA $50 \mathrm{mg} / \mathrm{kg} / \mathrm{day}$; and iii) ASA $5 \mathrm{mg} / \mathrm{kg} /$ day. Four months after surgery, the surviving animals were sacrificed and the rat esophagi were assessed for histological and biochemical [prostaglandin $\mathrm{E}_{2}\left(\mathrm{PGE}_{2}\right)$ and lipoxin $\mathrm{A}_{4}\left(\mathrm{LXA}_{4}\right)$ levels] analysis. As in the control rats, those receiving aspirin treatment showed no decrease in inflammation grade, extent of ulcerated esophageal mucosa, length of intestinal metaplasia in continuity with anastomosis, presence of intestinal metaplasia beyond anastomosis, severity of dysplasia or incidence of adenocarcinoma. In contrast, aspirin-treated rats showed decreased esophageal tissue levels of $\mathrm{PGE}_{2}$ and increased $\mathrm{LXA}_{4}$, significantly in the high-dose aspirin group $(\mathrm{P}=0.008$ and $\mathrm{P}=0.01$, respectively). In this rat model of gastroesophageal reflux, the administration of aspirin modified esophageal tissue levels of $\mathrm{PGE}_{2}$ and $\mathrm{LXA}_{4}$, but was not effective in preventing the development of esophageal adenocarcinoma.
\end{abstract}

Correspondence to: Dr Elena Piazuelo, Centro de Investigación Biomédica de Aragón (CIBA), Avda. San Juan Bosco 13, 50009 Zaragoza, Spain

E-mail: epiazor@unizar.es

Key words: intestinal metaplasia, esophageal adenocarcinoma, aspirin, $\mathrm{PGE}_{2}, \mathrm{LXA}_{4}$

\section{Introduction}

The incidence of esophageal adenocarcinoma (EA) has risen rapidly in the last two decades (1-3). Since EA is associated with poor prognosis, recent studies have mainly focused on prevention. Barrett's esophagus (BE) is the precursor lesion of EA, associated with gastroesophageal reflux disease (GERD) which heralds the sequence: GERD, inflammation, BE, lowgrade dysplasia, high-grade dysplasia, carcinoma in situ and invasive adenocarcinoma (4).

Numerous epidemiological studies have demonstrated a protective effect of non-steroidal anti-inflammatory drugs (NSAIDs), including acetylsalicylic acid (ASA), against several types of gastrointestinal tumors and EA (5). The main effect of NSAIDs and ASA appears to be inhibition of cyclooxygenase enzymes (COX-1 and COX-2) which are involved in the synthesis of prostaglandins. Several in vivo animal studies in experimental models of chronic esophagitis and EA have shown that COX-2 is overexpressed during the GERD-EA sequence. In these studies, the administration of COX inhibitors reduced the incidence of esophageal cancer. In addition, upregulation of COX-2 has been described at both the mRNA and protein levels in humans with GERD, BE or EA (6).

Although the protective effect of NSAIDs against several gastrointestinal (GI) tumors has been well demonstrated, the long-term use of these drugs or the newer and safer COX-2 selective inhibitors as chemopreventive agents has been dismissed due to their adverse cardiovascular effects $(7,8)$. Aspirin is the only drug that combines a protective effect on the cardiovascular system and the prevention of some types of GI cancer $(9,10)$.

The aim of the present study was to ascertain whether the administration of aspirin prevents the development of EA in a rat model of gastroesophageal reflux.

\section{Materials and methods}

Animals. All animal studies were carried out in the Animal Research Unit of the University of Zaragoza, an officially 
recognized research establishment that practices adequate husbandry; all research animals were individually housed and used in accordance with the Good Laboratory Practice guidelines. All procedures were approved by the University of Zaragoza Ethics Committee for Animal Experiments. The care and use of animals were performed in accordance with the Spanish Policy for Animal Protection RD1201/05, which meets the European Union Directive 86/609 on the protection of animals used for experimental and other scientific purposes. Throughout the experiment, all rats were housed in specifically designed cages (EU Dim; IFFA Credo) and kept in computer-controlled conditions of light (12-h light/dark cycle), noise $(45-50 \mathrm{~dB})$, temperature $\left(21 \pm 2^{\circ} \mathrm{C}\right)$ and humidity $(60-70 \%)$. The animals were cared for by veterinary staff. A total of 50 5-week-old female Wistar rats (Harlan Laboratories, Inc., Barcelona, Spain) weighing 220-300 g were used for the present study.

Experimental model. Solid food was withdrawn for $24 \mathrm{~h}$ and water for 6-8 h before surgery. Anesthesia was induced and maintained with an isoflurane-air mixture. Before surgery, an intramuscular injection of $100 \mathrm{mg} / \mathrm{kg}$ body weight cefazoline (Kefol; Lilly, Madrid, Spain) was administered as antibiotic prophylaxis. Rats underwent esophagojejunostomy with gastric preservation, allowing the gastroduodenal content to flow back into the esophagus. Surgery was performed according to a previously described protocol (11). This model is widely used since it reproduces the sequence of histological changes that occur in human esophageal adenocarcinogenesis and shows morphological and phenotypic characteristics similar to those observed in human Barrett's esophagus and associated adenocarcinoma, including mucin features and expression of differentiation markers and markers of neoplastic progression $(12,13)$. After surgery, the rats were housed in hanging cages to prevent bed ingestion and allowed to drink water ad libitum, with fasting until day 3 . Water with $0.3 \mathrm{mg} /$ ml buprenorphine (Buprex; Esteve, Barcelona, Spain) was provided during the first 72 postoperative hours. An additional intramuscular injection of cefazoline was administered $24 \mathrm{~h}$ after surgery. Rats received $50 \mathrm{mg} / \mathrm{kg}$ iron dextran (Difortin; Econatura, Madrid, Spain) intramuscularly once every 4 weeks until the end of the experiment. Rats were sacrificed by carbon dioxide inhalation 4 months after surgery. A blood sample was obtained for drug analysis from all of the animals immediately before death. Immediately after death, the entire esophagus with $0.5 \mathrm{~cm}$ of the jejunum (including the anastomosis) was removed, and the specimen was opened longitudinally. In all cases, biochemical determinations were performed in the area of the esophagus proximal to the anastomosis, where the sequence inflammation-intestinal metaplasia-dysplasia-adenocarcinoma takes place in this model. For these purposes, two 1-mm-wide longitudinal slices were cut out of the lower half of the esophagus and frozen immediately in liquid nitrogen. These were stored at $-80^{\circ} \mathrm{C}$ until biochemical studies were performed. The rest of the esophageal specimen was prepared for pathological study.

General design of the experiment. Two weeks after surgery, the 50 surviving rats were randomly divided into three groups: Group I: $n=17$, control (vehicle); Group II: $n=16$, treatment with
ASA $50 \mathrm{mg} / \mathrm{kg}$ body weight per day; Group III: $\mathrm{n}=17$, treatment with ASA $5 \mathrm{mg} / \mathrm{kg}$ body weight per day. Only those rats that were sacrificed at the time designated by the protocol were finally included in the study. As we observed in a previous study (11), reactive changes and intestinal metaplasia in continuity to the anastomotic site appeared at high rates in the first month, while the prevalence of metaplasia distant from the anastomosis increased considerably in month 2 . High rates of $\mathrm{AC}$ were found in month 4 ; thus, we considered this time of follow-up to be sufficient for our study.

Drug administration and dosage selection. Acetylsalicylic acid (ASA) (Sigma, Munich, Germany) was administered daily at two different doses: $5 \mathrm{mg} / \mathrm{kg}$ body weight per day (low dose) and $50 \mathrm{mg} / \mathrm{kg}$ body weight per day (high dose). These doses match those prescribed to patients in different clinical settings and have also been shown to be effective in previous studies of colon adenocarcinoma chemoprevention in rats and intestinal adenoma chemoprevention in mice (14-16). ASA was added to drinking water, replenished on a daily basis.

Histopathological analysis. Rat esophagi were examined by an experienced pathologist (C.C.) who was unaware of the experimental conditions. Changes in the squamous epithelium were classified into the following five categories. i) Reactive changes: characterized by the presence of basal cell hyperplasia, increased length of papillae, and hyperkeratosis with areas of inflammation and ulceration. ii) Columnar-lined metaplasia (intestinal metaplasia): squamous epithelium was replaced with columnar-lined epithelium comprising occasional and incompletely differentiated goblet cells; the length of the epithelial transformation was $>3 \mathrm{~mm}$ starting from the anastomosis site or was intercalated, or it could be observed beyond the surgical anastomosis, and was surrounded by squamous epithelium. iii) Dysplasia: characterized by nuclear atypia, partial loss of mucosecretory function and cell polarity and an increase in mitotic figures. Dysplasia was classified as low-grade dysplasia (LGD) and high-grade dysplasia (HGD) according to the criteria proposed by Haggit (17), as previously described in this experimental model (13). In LGD, the crypt architecture is preserved or minimally distorted; the nuclei may be stratified but without reaching the apical surface of glands, nuclei are enlarged, crowed and hyperchromatic, mitotic figures may be found in the upper portion of the crypt; goblet and columnar cell mucus is usually diminished or absent, but goblet cells in which the mucous droplet does not communicate with the luminal surface may be observed. The abnormalities extend to the mucosal surface. In HGD, distortion of crypt architecture is usually present and may be pronounced. It is composed of branching and lateral budding of crypts, a villiform configuration of the mucosal surface or intraglandular bridging of epithelium to form a cribriform pattern of 'back-to-back' glands. Nuclear abnormalities are present as in LGD, and stratification reaches the crypt luminal surface. There may be a loss of nuclear polarity, and nuclei often vary markedly in size, shape and staining characteristics. Goblet and columnar cell mucus is usually absent. The abnormalities extend to the mucosal surface. iv) Adenocarcinoma: glandular structures of dysplastic columnar epithelial with stromal invasion and deep infiltration. v) Squamous carci- 
Table I. Effect of ASA treatment on lesions in surviving rats.

\begin{tabular}{lccc}
\hline Group & $\mathrm{I}(\mathrm{n}=8)$ & $\mathrm{II}(\mathrm{n}=8)$ & $\mathrm{III}(\mathrm{n}=11)$ \\
\hline Inflammation & 8 & 8 & 11 \\
Ulcerated mucosa (\%) & 35 & 37.5 & 38.18 \\
Squamous hyperplasia (\%) & 87.5 & 87.5 & 100 \\
Intestinal metaplasia in continuity with anastomosis (mm) & 3.875 & 3.375 & 4.611 \\
Intestinal metaplasia beyond anastomosis (\%) & 62.5 & 75 & 45.5 \\
Dysplasia & 8 & 8 & 11 \\
High-grade dysplasia/low-grade dysplasia & $2 / 6$ & $2 / 6$ & $0 / 11$ \\
Carcinoma & 5 & 4 & 7 \\
\hline
\end{tabular}

noma: characterized by accumulation of atypical cells with nuclear hyperchromasia, abnormally clumped chromatin, and loss of polarity (13).

Measurement of prostaglandin levels in esophageal mucosa. All biochemical analyses were performed in the lower half of the esophagus. Tissue samples were introduced in $1 \mathrm{ml}$ of cold PBS containing indomethacin $(10 \mu \mathrm{M})$. They were homogenized (Heidolph DIAX 900) on ice and centrifuged $15 \mathrm{~min}$ at $1,200 \mathrm{rpm}$ and $4^{\circ} \mathrm{C}$. Supernatants were collected in 2-ml tubes. Prostaglandin extraction was performed as previously described by Powell et al (18). The concentration of $\mathrm{PGE}_{2}$ was measured using the Enzyme immunoassay kit from Amersham (Amersham Pharmacia Biotech, Inc., Piscataway, NJ, USA).

Measurement of 15-epi-lipoxin $A_{4}$ levels in esophageal $m u \cos a$. Tissue samples were homogenized in ethanol $(5 \mathrm{ml} / \mathrm{g})$ and centrifuged to obtain the supernatant. One milliliter of the supernatant was diluted with $5 \mathrm{ml}$ of deionized water and acidified to a $\mathrm{pH}$ of 3.5 with $\mathrm{HCl}$. 15-Epi-lipoxin $\mathrm{A}_{4}$ extraction and determination were performed according to the manufacturer's instructions (Oxford Biomedical Research, Rochester Hills, MI, USA).

Plasma drug concentration. Aspirin and salicylic acid plasma levels were measured by high performance liquid chromatography on a $4-\mu \mathrm{m}$ ultrasphere C18 silica column $(150 \times 3.9 \mathrm{~mm}$, Waters; Millipore Iberica, Madrid, Spain) according to a previously described method (19). Blood samples were placed in an ice water bath, treated with $10 \mu \mathrm{l} / \mathrm{ml}$ of $50 \%(\mathrm{v} / \mathrm{v})$ potassium fluoride (an enzyme inhibitor) to avoid aspirin hydrolysis, and centrifuged for $3 \mathrm{~min}$. The supernatant was then acidified and extracted with diethyl ether $(1: 3 ; \mathrm{v} / \mathrm{v})$ for $20 \mathrm{~min}$, which allows recoveries over $80 \%$. The organic phase of the extract was then evaporated under nitrogen and stored at $-20^{\circ} \mathrm{C}$. Samples were reconstituted in $500 \mu \mathrm{l}$ of mobile phase (acetonitrile/water/ TFA; 30/70/0,01; v:v), and $20 \mu 1$ aliquots of the reconstituted sample were analyzed using a reverse phase high performance liquid chromatography (Waters 600E; Millipore). Aspirin and its metabolite absorbances were measured at $237 \mathrm{~nm}$. Toluic acid (Sigma, St. Louis, MO, USA) was used as the internal standard $(20 \mu \mathrm{g} / \mathrm{ml})$. Aspirin and salicylic acid concentrations were determined by comparison of standards.
Statistical analysis. Data management and statistical analysis were performed using SPSS software. Results from the biochemical assays are expressed as mean \pm standard error (SE). Data were compared between groups by non-parametric tests (Kruskall-Wallis and Mann-Whitney); differences with a P-value $<0.05$ were considered to indicate statistically significant results. Fisher's exact test was used to analyze the qualitative variables. Multiple comparisons were corrected by means of the Bonferroni method.

\section{Results}

Twenty-seven rats survived to the end of the experiment (54\%). The main cause of death was asphyxia provoked by bedding intake.

Anatomopathological analysis. Macroscopically, all rats with esophagojejunostomy showed dilatation and thickening of the mid and lower esophagus, and the distal esophagus showed ulceration. Macroscopically, 2 rats from the highdose aspirin group presented esophageal tumors. All esophagi presented inflammatory infiltrate. In the upper third of the esophagus rats presented some erosion, and ulceration was observed in the proximity of the anastomosis. In most animals, the upper and the middle parts of the esophagus showed squamous hyperplasia. All operated-rat esophagi showed columnar-lined metaplasia in continuity with the jejunal epithelium. In addition, columnar-lined metaplasia was found far above the anastomosis in some animals. This metaplasia consisted of isolated or grouped goblet cells, forming glands in some cases. This type of metaplasia could only be identified microscopically.

Neoplastic transformation of the epithelium was always near the anastomosis, surrounded by columnar epithelium. Dysplasic changes were present in all rats to some degree. Histologically, all tumors were adenocarcinomas, and all but one (adenosquamous carcinoma in a low-dose aspirin rat) were of the mucinous type.

Effect of ASA treatment on lesions. Inflammation, ulceration, intestinal metaplasia and dysplasia were present in all rats (Table I). Treatment with either low- or high-dose aspirin did not modify the grade of inflammation or the extent of ulcerated mucosa. Metaplasia in continuity with anastomosis length 

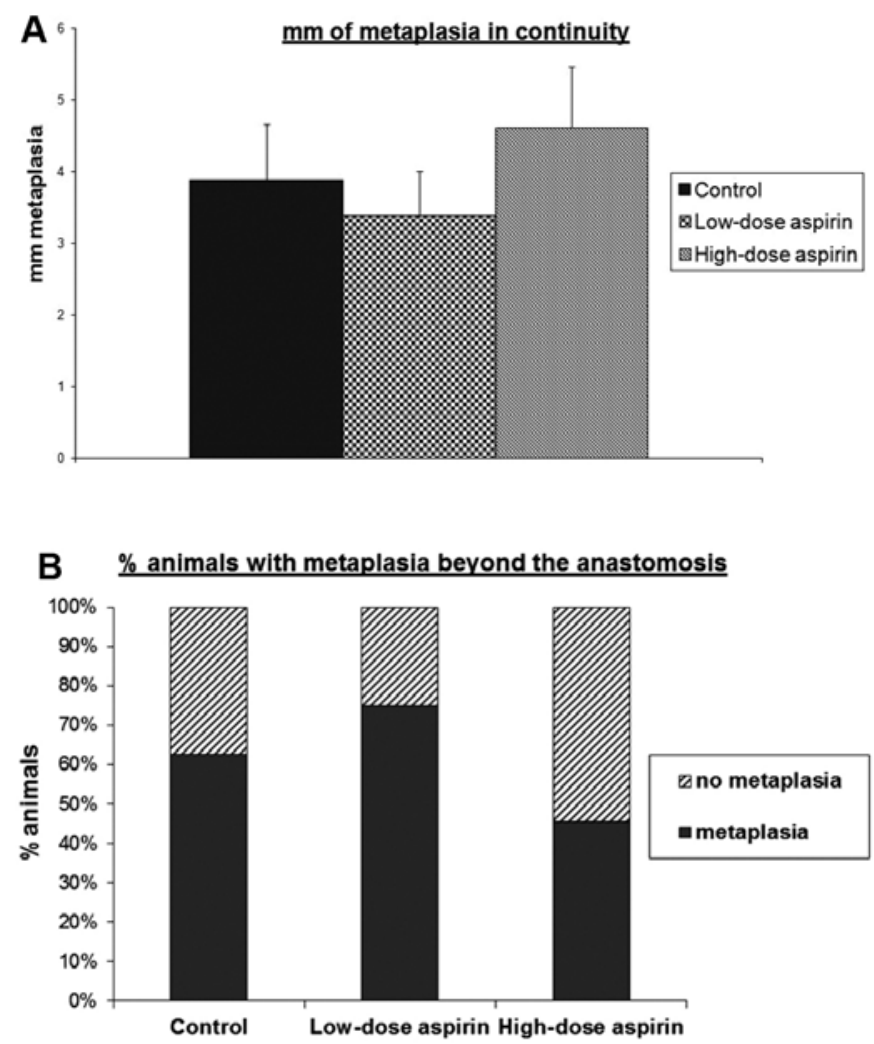

Figure 1. (A) Effect of treatment on metaplasia in continuity length. (B) Percentage of animals that developed metaplasia beyond the anastomosis. No differences between groups were found.

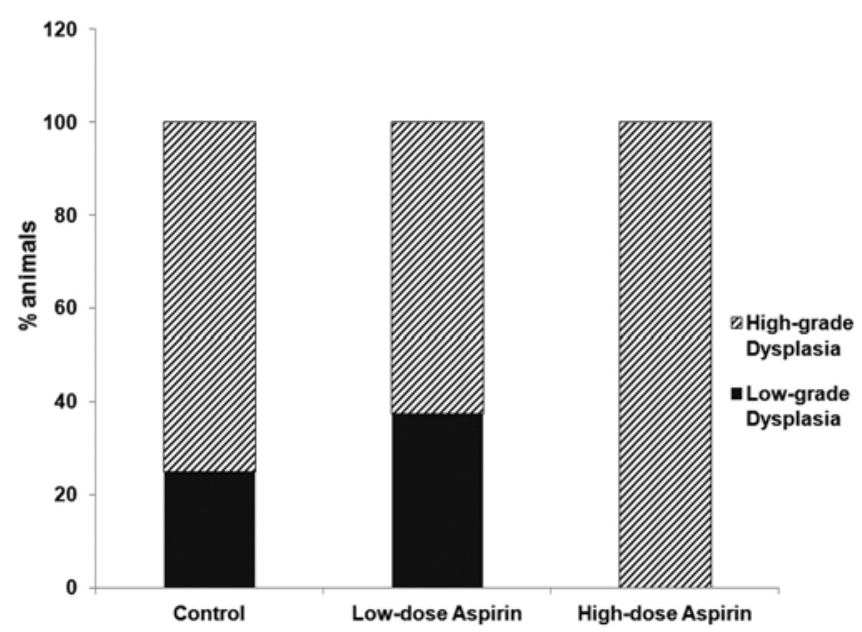

Figure 2. Percentage of animals that developed dysplasia (either low- or highgrade).

was not affected by aspirin treatment at any dose (Fig. 1). The majority (62.5\%) of control (vehicle) rats developed metaplasia beyond the anastomosis. This type of metaplasia was also found in the rats treated with aspirin: $45.5 \%$ of rats treated with high-dose ASA and $75 \%$ of rats treated with low-dose ASA. All rats developed dysplasia. No differences between groups were observed including differences in low- vs. highgrade dysplasia (Fig. 2). The number of rats that presented neoplasia in the low-dose aspirin group was lower than the

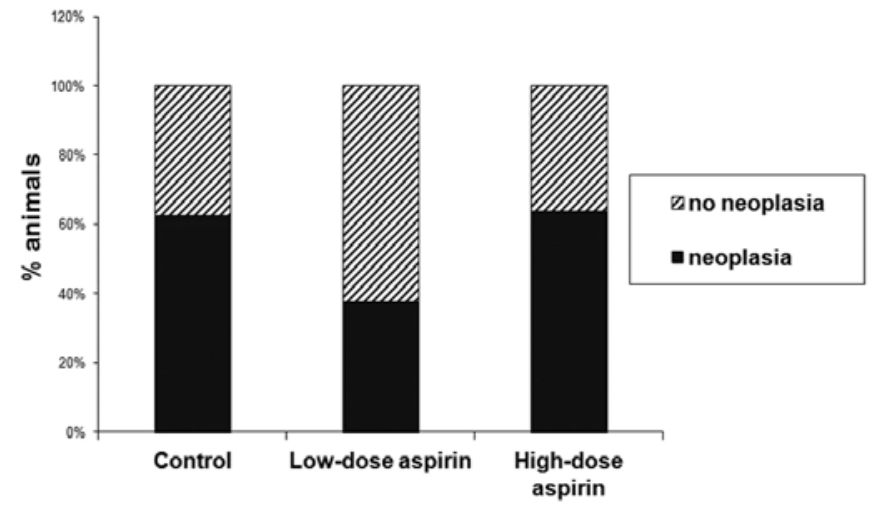

Figure 3. Percentage of animals that developed neoplasia.

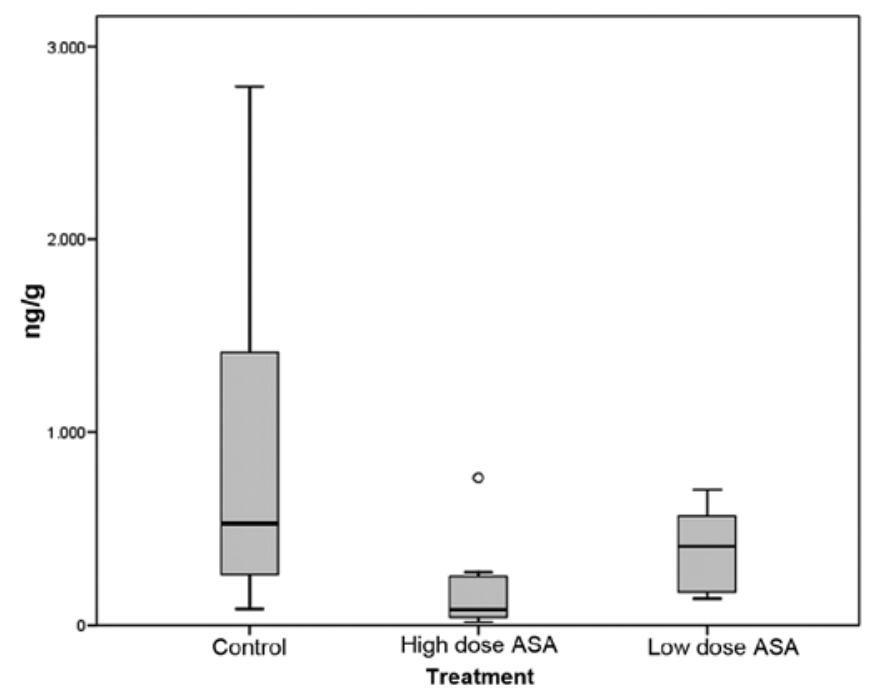

Figure 4. $\mathrm{PGE}_{2}$ level in rat esophageal tissue. In both treatment groups, the $\mathrm{PGE}_{2}$ level was decreased compared to the control group. $\mathrm{PGE}_{2}$ levels in the high-dose group were significantly decreased $(\mathrm{P}=0.008)$. $^{\circ}$ Represents an outlier.

numbers in the other two groups, but these differences were not significant (Fig. 3).

Prostaglandin $E_{2}$ and 15-epi-lipoxin $A_{4}$ levels. We observed a decrease in $\mathrm{PGE}_{2}$ levels in the esophageal tissue in both the high-dose and low-dose aspirin groups (183.17 \pm 65.68 and $391.02 \pm 76.40 \mathrm{ng} / \mathrm{g}$ tissue; mean \pm SEM, respectively) compared to the control group $(910.80 \pm 324.98 \mathrm{ng} / \mathrm{g} ; \mathrm{P}=0.08$ and $\mathrm{P}=0.401$, respectively) (Fig. 4).

Regarding the impact of aspirin on lipoxin $\mathrm{A}_{4}$ production in this model, in both the high-dose and low-dose aspirin groups we observed an increase in 15-epi-lipoxin $\mathrm{A}_{4}$ in the esophagi (2096.38 ng/g \pm 820.40 and $424.53 \mathrm{ng} / \mathrm{g} \pm 281.00$; mean \pm SEM, respectively) when compared to the controls $(267.60 \mathrm{ng} / \mathrm{g} \pm$ 250.83; $\mathrm{P}=0.01$ and $\mathrm{P}=0.203$, respectively) (Fig. 5).

Plasma drug concentrations. All rats receiving ASA showed detectable levels of salicylic acid (SA) in the plasma. Plasma drug concentration of SA in rats receiving $50 \mathrm{mg} / \mathrm{kg}$ was $57.28 \pm 1.61 \mu \mathrm{g} / \mathrm{ml}$. Rats receiving $5 \mathrm{mg} / \mathrm{kg}$ had a plasma level 




Figure 5. $\mathrm{LXA}_{4}$ levels in rat esophageal tissue. $\mathrm{LXA}_{4}$ levels in the high-dose group were significantly increased compared to the control group $(\mathrm{P}=0.01)$.

of SA of $3.94 \pm 0.29 \mu \mathrm{g} / \mathrm{ml}$ (mean $\pm \mathrm{SE}$ ). As expected, the rats in the control group did not have detectable ASA or SA levels.

\section{Discussion}

In the present study, we attempted to assess whether the administration of aspirin prevents the development of esophageal adenocarcinoma in vivo. The surgical model of Barrett's esophagus and esophageal adenocarcinoma in the rat appears to be a suitable model of human disease (12). Regarding the COX pathway, COX2, prostaglandin E synthase, prostaglandin receptors $\mathrm{E}_{2}$ and $\mathrm{E}_{4}$ overexpression and $\mathrm{PGE}_{2}$ overproduction have been observed during rat esophageal adenocarcinogenesis $(20,21)$, mimicking the expression profiles of these markers in both human Barrett's and esophageal adenocarcinoma $(22,23)$. Administration of different COX inhibitors has been shown to provoke a significant reduction in $\mathrm{PGE}_{2}$ production as well as to prevent the development of adenocarcinoma in this experimental model (24-27).

The best known molecular target of aspirin is COX. ASA, but not other NSAIDs, can cause irreversible inactivation of COX isozymes through the acetylation of a specific serine moiety (Ser 529 of COX-1 and Ser 516 of COX-2) (28). In contrast to other NSAIDs, ASA-mediated acetylation of COX-2 provokes a change in the active enzyme site leading to incomplete reaction of arachidonic acid. The product of this reaction is $15 R$ hydroxyeicosatetraenoic acid (15R-HETE), which is rapidly metabolized by lipoxygenase enzyme to 15-epi-lipoxin $\mathrm{A}_{4}$, also called aspirin-triggered lipoxin (ATL) (29). ATLs have been shown to exert potent anti-inflammatory effects (30). Additionally, lipoxin $\mathrm{A}_{4}\left(\mathrm{LXA}_{4}\right)$ has been shown to reduce cell proliferation, inhibit tumor cell invasion, and suppress experimental tumor growth $(31,32)$.

The ability of aspirin to inhibit COX-2 activity in vivo depends mainly on the dose administered. It is noteworthy that systemic concentrations of aspirin reached after the administration of low doses are inadequate to significantly acetylate COX-2. At higher doses, aspirin may affect COX-2 in a dose-dependent fashion. It can be hypothesized that local aspirin concentrations in the digestive system, including the colon and esophagus, after dosing with the drug, are sufficiently high to acetylate epithelial COX isozymes (33). In one study in humans, inhibition of $\mathrm{PGE}_{2}$ was detected in rectal biopsies performed after 1 month of treatment with three aspirin doses (81, 325 and $650 \mathrm{mg}$ ) (34). Unexpectedly, the 81-mg daily aspirin dose also suppressed $\mathrm{PGE}_{2}$ levels to the same extent as did the 650-mg dose. In the esophagus, it has been shown that administration of aspirin at a dose of $325 \mathrm{mg}$ daily in conjunction with esomeprazole administered for 10 days resulted in lower esophageal mucosal content in patients with Barrett's esophagus, whereas esomeprazole alone or in combination with rofecoxib did not reduce $\mathrm{PGE}_{2}$ production (35). Recently, a randomized, double-blind, placebo controlled phase-II 28-day trial compared the effect of 2 dose levels of aspirin in combination with esomeprazole on tissue $\mathrm{PGE}_{2}$ concentration in patients with Barrett's esophagus (36). The results revealed that $325 \mathrm{mg}$ aspirin daily, but not $81 \mathrm{mg}$, significantly reduced tissue concentrations of $\mathrm{PGE}_{2}$ compared with a placebo. In the present study, we used two different doses of aspirin, the lower dose ( $5 \mathrm{mg} / \mathrm{kg} /$ day $)$, which would be equivalent to $300-350 \mathrm{mg} /$ day for a body weight of $60-70 \mathrm{~kg}$, and a higher dose of $50 \mathrm{mg} / \mathrm{kg} /$ day, which would correspond to a high anti-inflammatory dose in humans. The rationale for the use of such a high dose was to test whether the lower dose of aspirin was equally effective in inhibiting COX activity. Thus, although $\mathrm{PGE}_{2}$ levels showed a tendency to decrease in the low-dose aspirin group, the differences were not statistically significant. The lack of a significant effect might be due to a lack of power due to the high variability of $\mathrm{PGE}_{2}$ in the non-treated control group and not a true lack of efficacy of this dose of aspirin to inhibit $\mathrm{PGE}_{2}$ synthesis in the esophageal mucosa. As expected, a profound and significant decrease in $\mathrm{PGE}_{2}$ content was observed in the high-dose aspirin group, indicating that administration of aspirin indeed led to an inhibition of COX activity at the esophageal level.

The present study also investigated the generation of ATL, the other lipid mediator generated by aspirin-acetylated COX-2. Our data showed the generation of 15(R) epi-LXA in the absence of aspirin in this experimental model. Furthermore, production of aspirin-triggered 15-epi-lipoxin $\mathrm{A}_{4}$ in rat esophagi was increased in a dose-dependent manner in animals receiving aspirin, but only in the high-dose group were these levels significantly higher than that in the control group. These data indicate that high doses of ASA are necessary to acetylate COX-2 isoenzyme in the esophagus and argue against the idea that ATLs are produced mainly with low-dose rather than high-dose aspirin (37). There are no previous studies exploring the role of lipoxins in the esophagus, but previous reports have shown that $\mathrm{LXA}_{4}$ exerts potent protective effects in the stomach. Thus, in an experimental model of gastritis induced by iodoacetamide, Souza et al (38) observed that, after the administration of aspirin (50 or $100 \mathrm{mg} / \mathrm{kg}$ ), the levels of $\mathrm{LXA}_{4}$ in gastric mucosa of rats with gastritis were significantly higher than in healthy rats. Moreover, the presence of $\mathrm{LXA}_{4}$ reduced the mucosal injury provoked by aspirin intake. Consistently with these results, Fiorucci et al (39) showed that $\mathrm{LXA}_{4}$ production in the stomach was significantly increased in rats treated with aspirin $(50 \mathrm{mg} / \mathrm{kg})$ in an experimental 
model of acute gastric damage provoked by aspirin. In that rat model, intraperitoneal pretreatment with $\mathrm{LXA}_{4}$ reduced the severity of aspirin-induced gastric injury in a dose-dependent manner. In addition to this, the intraperitoneal administration of an $\mathrm{LXA}_{4}$ receptor antagonist led to a significantly increased aspirin-induced gastric damage.

In the present study, we observed the expected effect of aspirin in esophageal tissues at the biochemical level, which was a dose-dependent decrease in $\mathrm{PGE}_{2}$ content and an increase in ATL production. However, this effect was not accompanied by any improvement at the histological level at any dose. Thus, administration of aspirin did not lead to any reduction in the area of ulcerated mucosa, the length of metaplasia in continuity with anastomosis, the incidence of metaplasia beyond the anastomosis, the severity of dysplasia, or the incidence of adenocarcinoma. These results are consistent with previous reports. Pawlik et al (40), in an experimental model of acute reflux esophagitis, showed that aspirin from $12.5 \mathrm{mg} / \mathrm{kg} /$ day to $100 \mathrm{mg} / \mathrm{kg} /$ day significantly inhibited prostaglandin synthesis. In parallel, aspirin provoked a significant decrease in esophageal blood flow and an increase in acute esophagitis. In another study, using the same experimental model as we employed, Rizvi et al (41) found no differences in the rate of esophageal adenocarcinoma evaluated 8 months after esophagojejunostomy in rats receiving aspirin in the diet compared with a control group. The reasons for the absence of a correlation between the biochemical and histological effects of aspirin in this model warrant further investigation. One possible explanation is that in Barrett's carcinogenesis it would be necessary to target not only the consequence of injury (inflammation-associated pathway) but also the cause of injury. This hypothesis is supported by Rizvi et al (41), who demonstrated that the combination of aspirin with ursodeoxycolic acid (which reduces the concentration of bile salts), but not each agent individually, reduced the risk of esophageal adenocarcinoma in a rat model of esophagojejunostomy. On the other hand, we cannot ignore the fact that, in addition to its anti-inflammatory effect, aspirin can also induce gastrointestinal damage through a variety of mechanisms. Some clinical trials have observed that even low-dose aspirin treatment provokes esophageal damage $(42,43)$. It has been shown that aspirin makes the esophageal mucosa more sensitive to the injurious action of acid and pepsin (44). In another study, intragastric administration of aspirin induced dilated intercellular spaces in the rat esophageal epithelium (45). In addition, some studies have observed that treatment with high doses of ASA provokes both significantly increased production of reactive oxygen species (ROS) (46) and inhibition of ROS scavenger activity (47). Since the involvement of ROS in the development of esophageal adenocarcinoma has been previously demonstrated in this experimental model (11), another possibility could be that the potential benefits derived from inhibition of COX activity are counterbalanced by a deleterious effect through ROS generation.

In conclusion, the present study demonstrated that aspirin, at a high dose, affects COX activity, hence producing a profound inhibition of $\mathrm{PGE}_{2}$ content and the generation of aspirin-triggered lipoxins in esophageal tissues, but failed to demonstrate any potential benefit in the prevention of esophageal adenocarcinoma in this rat model of gastroesophageal reflux. Further studies are necessary to elucidate how aspirin acts at the esophagus and the mechanisms underlying the protective role that epidemiological studies have shown for aspirin against esophageal adenocarcinoma.

\section{References}

1. Pera M, Manterola C, Vidal O and Grande L: Epidemiology of esophageal adenocarcinoma. J Surg Oncol 92: 151-159, 2005.

2. Blot WJ, Devesa SS, Kneller RW and Fraumeni JF Jr: Rising incidence of adenocarcinoma of the esophagus and gastric cardia. JAMA 265: 1287-1289, 1991

3. Devesa SS, Blot WJ and Fraumeni JF Jr: Changing patterns in the incidence of esophageal and gastric carcinoma in the United States. Cancer 83: 2049-2053, 1998.

4. Mutoh M, Watanabe K, Kitamura T, Shoji Y, Takahashi M, Kawamori T, Tani K, Kobayashi M, Maruyama T, Kobayashi K, Ohuchida S, Sugimoto Y, Narumiya S, Sugimura T and Wakabayashi K: Involvement of prostaglandin E receptor subtype $\mathrm{EP}_{4}$ in colon carcinogenesis. Cancer Res 62: 28-32, 2002.

5. Husain SS, Szabo IL and Tamawski AS: NSAID inhibition of GI cancer growth: clinical implications and molecular mechanisms of action. Am J Gastroenterol 97: 542-553, 2002.

6. Piazuelo E, Jimenez P and Lanas A: COX-2 inhibition in esophagitis, Barrett's esophagus and esophageal cancer. Curr Pharm Des 9: 2267-2280, 2003.

7. Al-Saeed A: Gastrointestinal and cardiovascular risk of nonsteroidal anti-inflammatory drugs. Oman Med 26: 385-391 2011.

8. Patrignani P, Tacconelli S, Bruno A, Sostres C and Lanas A: Managing the adverse effects of nonsteroidal anti-inflammatory drugs. Expert Rev Clin Pharmacol 4: 605-621, 2011.

9. Hennekens $\mathrm{CH}$ : Update on aspirin in the treatment and prevention of cardiovascular disease. Am Heart J 137: S9-S13, 1999.

10. Dai Y and Ge J: Clinical use of aspirin in treatment and prevention of cardiovascular disease. Thrombosis 2012: 245037, 2012.

11. Piazuelo E, Cebrián C, Escartín A, Jiménez P, Soteras F, Ortego J and Lanas A: Superoxide dismutase prevents development of adenocarcinoma in a rat model of Barrett's esophagus. World $\mathrm{J}$ Gastroenterol 11: 7436-7443, 2005.

12. Hindmarsh A, Belshaw N, Mehta S, Johnson IT and Rhodes M: Can the rat be used as a valid model of human esophageal adenocarcinoma? Dis Esophagus 25: 159-165, 2011.

13. Su Y, Chen X, Klein M, Fang M, Wang S, Yang CS and Goyal RK: Phenotype of columnar-lined esophagus in rats with esophagogastroduodenal anastomosis: similarity to human Barrett's esophagus. Lab Invest 84: 753-765, 2004.

14. Reddy BS, Rao CV, Rivenson A and Kelloff G: Inhibitory effect of aspirin on azoxymethane-induced colon carcinogenesis in F344 rats. Carcinogenesis 14: 1493-1497, 1993.

15. Barnes CJ and Lee M: Chemoprevention of spontaneous intestinal adenomas in the adenomatous polyposis coli Min mouse model with aspirin. Gastroenterology 114: 873-877, 1998.

16. Bousserouel S, Gosse F, Bouhadjar M, Soler L, Marescaux J and Rau F: Long-term administration of aspirin inhibits tumour formation and triggers anti-neoplastic molecular changes in a pre-clinical model of colon carcinogenesis. Oncol Rep 23: 511-517, 2010.

17. Haggitt RC: Barrett's esophagus, dysplasia, and adenocarcinoma. Hum Pathol 25: 982-993, 1994.

18. Powell WS: Reversed-phase high-pressure liquid chromatography of arachidonic acid metabolites formed by cyclooxygenase and lipoxygenases. Anal Biochem 148: 59-69, 1985.

19. Lanas AI, Arroyo MT, Esteva F, Cornudella R, Hirschowitz BI and Sáinz R: Aspirin related gastrointestinal bleeders have an exaggerated bleeding time response due to aspirin use. Gut 39: 654-660, 1996.

20. Jang TJ, Min SK, Bae JD, Jung KH, Lee JI, Kim JR and Ahn WS: Expression of cyclooxygenase 2, microsomal prostaglandin $\mathrm{E}$ synthase 1, and EP receptors is increased in rat oesophageal squamous cell dysplasia and Barrett's metaplasia induced by duodenal contents reflux. Gut 53: 27-33, 2004.

21. Piazuelo E, Santander S, Cebrián C, Jiménez P, Pastor C, García-González MA, Esteva F, Esquivias P, Ortego J and Lanas A: Characterization of the prostaglandin E2 pathway in a rat model of esophageal adenocarcinoma. Curr Cancer Drug Targets 12: 132-143, 2012. 
22. Wilson KT, Fu S, Ramanujam KS and Meltzer SJ: Increased expression of inducible nitric oxide synthase and cyclooxygenase-2 in Barrett's esophagus and associated adenocarcinomas. Cancer Res 58: 2929-2934, 1998.

23. Jimenez P, Piazuelo E, Cebrian C, Ortego J, Strunk M, GarcíaGonzalez MA, Santander S, Alcedo J and Lanas A: Prostaglandin EP2 receptor expression is increased in Barrett's oesophagus and oesophageal adenocarcinoma. Aliment Pharmacol Ther 31: $440-451,2010$

24. Esquivias P, Morandeira A, Escartín A, Cebrián C, Santander S, Esteva F, García-González MA, Ortego J, Lanas A and Piazuelo E: Indomethacin but not a selective cyclooxygenase-2 inhibitor inhibits esophageal adenocarcinogenesis in rats. World J Gastroenterol 18: 4866-4874, 2012.

25. Buttar NS, Wang KK, Leontovich O, Westcott JY, Pacifico RJ, Anderson MA, Krishnadath KK, Lutzke LS and Burgart LJ: Chemoprevention of esophageal adenocarcinoma by COX-2 inhibitors in an animal model of Barrett's esophagus. Gastroenterology 122: 1101-1112, 2002.

26. Oyama K, Fujimura T, Ninomiya I, Miyashita T, Kinami S, Fushida S, Ohta T and Koichi M: A COX-2 inhibitor prevents the esophageal inflammation-metaplasia-adenocarcinoma sequence in rats. Carcinogenesis 26: 565-570, 2005.

27. Chen X, Wang S, Wu N, Sood S, Wang P, Jin Z, Beer DG, Giordano TJ, Lin Y, Shih WC, Lubet RA and Yang CS Overexpression of 5-lipoxygenase in rat and human esophageal adenocarcinoma and inhibitory effects of zileuton and celecoxib on carcinogenesis. Clin Cancer Res 10: 6703-6709, 2004.

28. Patrono C and Rocca B: Aspirin: promise and resistance in the new millennium. Arterioscler Thromb Vasc Biol 28: s25-s32, 2008.

29. Claria J and Serhan CN: Aspirin triggers previously undescribed bioactive eicosanoids by human endothelial cell-leukocyte interactions. Proc Natl Acad Sci USA 92: 9475-9479, 1995.

30. Morris T, Stables M, Hobbs A, de Souza P, Colville-Nash P, Warner T, Newson J, Bellingan G and Gilroy DW: Effects of low-dose aspirin on acute inflammatory responses in humans. J Immunol 183: 2089-2096, 2009.

31. Zhou XY, Li YS, Wu P, Wang HM, Cai ZY, Xu FY and Ye DY: Lipoxin $\mathrm{A}_{4}$ inhibited hepatocyte growth factor-induced invasion of human hepatoma cells. Hepatol Res 39: 921-930, 2009.

32. Chen Y, Hao H, He S, Cai L, Li Y, Hu S, Ye D, Hoidal J, Wu P and Chen X: Lipoxin $\mathrm{A}_{4}$ and its analogue suppress the tumor growth of transplanted $\mathrm{H} 22$ in mice: the role of antiangiogenesis. Mol Cancer Ther 9: 2164-2174, 2010.

33. Dovizio M, Tacconelli S, Sostres C, Ricciotti E and Patrignani P: Mechanistic and pharmacological issues of aspirin as an anticancer agent. Pharmaceuticals 5: 1346-1371, 2012.

34. Sample D, Wargovich M, Fischer SM, Inamdar N, Schwartz P, Wang X, Do KA and Sinicrope FA: A dose-finding study of aspirin for chemoprevention utilizing rectal mucosal prostaglandin $\mathrm{E}_{2}$ levels as a biomarker. Cancer Epidemiol Biomarkers Prev 11: 275-279, 2002.

35. Triadafilopoulos G, Kaur B, Sood S, Traxler B, Levine D and Weston A: The effects of esomeprazole combined with aspirin or rofecoxib on prostaglandin $\mathrm{E}_{2}$ production in patients with Barrett's oesophagus. Aliment Pharmacol Ther 23: 997-1005, 2006.
36. Falk GW, Buttar NS, Foster NR, Ziegler KL, Demars CJ, Romero Y, Marcon NE, Schnell T, Corley DA, Sharma P, Cruz-Correa MR, Hur C, Fleischer DE, Chak A, Devault KR, Weinberg DS, Della'Zanna G, Richmond E, Smyrk TC, Mandrekar SJ and Limburg PJ; Cancer Prevention Network: A combination of esomeprazole and aspirin reduces tissue concentrations of prostaglandin $\mathrm{E}_{2}$ in patients with Barrett's esophagus. Gastroenterology 143: 917-926.e1, 2012.

37. Chiang N, Bermudez EA, Ridker PM, Hurwitz S and Serhan CN: Aspirin triggers antiinflammatory 15-epi-lipoxin $\mathrm{A}_{4}$ and inhibits thromboxane in a randomized human trial. Proc Natl Acad Sci USA 101: 15178-15183, 2004.

38. Souza MH, de Lima OM Jr, Zamuner SR, Fiorucci S and Wallace JL: Gastritis increases resistance to aspirin-induced mucosal injury via COX-2-mediated lipoxin synthesis. Am J Physiol Gastrointest Liver Physiol 285: G54-G61, 2003.

39. Fiorucci S, de Lima OM Jr, Mencarelli A, Palazzetti B, Distrutti E, McKnight W, Dicay M, Ma L, Romano M, Morelli A and Wallace JL: Cyclooxygenase-2-derived lipoxin $\mathrm{A}_{4}$ increases gastric resistance to aspirin-induced damage. Gastroenterology 123: 1598-1606, 2002.

40. Pawlik M, Pajdo R, Kwiecien S, Ptak-Belowska A, Sliwowski Z, Mazurkiewicz-Janik M, Konturek SJ, Pawlik WW and Brzozowski T: Nitric oxide (NO)-releasing aspirin exhibits a potent esophagoprotection in experimental model of acute reflux esophagitis. Role of nitric oxide and proinflammatory cytokines. J Physiol Pharmacol 62: 75-86, 2011.

41. Rizvi S, Demars CJ, Comba A, Gainullin VG, Rizvi Z, Almada LL, Wang K, Lomberk G, Fernández-Zapico ME and Buttar NS: Combinatorial chemoprevention reveals a novel smoothened-independent role of GLI1 in esophageal carcinogenesis. Cancer Res 70: 6787-6796, 2010.

42. Sugimoto M, Nishino M, Kodaira C, Yamade M, Ikuma M, Tanaka T, Sugimura H, Hishida A and Furuta T: Esophageal mucosal injury with low-dose aspirin and its prevention by rabeprazole. J Clin Pharmacol 50: 320-330, 2010.

43. Kawai T, Watanabe $M$ and Yamashina A: Impact of upper gastrointestinal lesions in patients on low-dose aspirin therapy: preliminary study. J Gastroenterol Hepatol 25 (Suppl 1): S23-S30, 2010.

44. Lanas A, Jiménez P, Ferrández A, Escartín A, Arenas J, Esteva F and Ortego J: Selective COX-2 inhibition is associated with decreased mucosal damage induced by acid and pepsin in rabbit esophagitis. Inflammation 27: 21-29, 2003.

45. Zhang DH, Zhou LY, Dong XY, Cui RL, Xue Y and Lin SR: Factors influencing intercellular spaces in the rat esophageal epithelium. World J Gastroenterol 16: 1063-1069, 2010.

46. Pohle T, Brzozowski T, Becker JC, Van der Voort IR, Markmann A, Konturek SJ, Moniczewski A, Domschke W and Konturek JW: Role of reactive oxygen metabolites in aspirininduced gastric damage in humans: gastroprotection by vitamin C. Aliment Pharmacol Ther 15: 677-687, 2001.

47. Raza H, John A and Benedict S: Acetylsalicylic acid-induced oxidative stress, cell cycle arrest, apoptosis and mitochondrial dysfunction in human hepatoma HepG2 cells. Eur J Pharmacol 668: 15-24, 2011. 